\title{
Preparation of siloxane-containing vaterite/poly (L-lactic acid) hybrid microbeads with silicate and calcium ions-releasing ability
}

\author{
Jin NAKAMURA, Gowsihan POOLOGASUNDARAMPILLAI, Akiko OBATA and Toshihiro KASUGA ${ }^{\dagger}$
}

Department of Frontier Materials, Graduate School of Engineering, Nagoya Institute of Technology, Gokiso-cho, Showa-ku, Nagoya 466-8555

\begin{abstract}
Siloxane-containing vaterite (SiV)/poly (L-lactic acid) (PLLA) hybrids have the releasing-ability of silicate and calcium ions for gene-activation. In the present paper a new types of beads were prepared using the hybrids via an electrospraying method. The diameters of the beads were controlled in the range of $\sim 65$ to $\sim 180 \mu \mathrm{m}$ by increasing the feeding rate from 0.1 to $0.9 \mathrm{ml} / \mathrm{min}$. Depressed areas could be observed on the surface of the beads. The SiV particles with concentration of 10 and $20 \mathrm{wt} \%$ in the beads were completely enclosed by the PLLA matrix. These beads showed the controlled release of silicate and calcium ions in Tris buffer solution.
\end{abstract}

(C2010 The Ceramic Society of Japan. All rights reserved.

Key-words : Poly (L-lactic acid), Vaterite, Siloxane, Beads, Electrospray, lon-releasing ability

[Received February 22, 2010; Accepted April 15, 2010]

\section{Introduction}

Third generation biomaterials are those which are biocompatible, bioresorbable and bioactive (osteoconductive and osteoinductive). ${ }^{1)}$ Bioactive materials posses the ability to form bond to bone and some even enhance bone formation by stimulating genes in cells to proliferate and differentiate into bone cells. These properties of those materials are due to the controlled releases of silicate and calcium ions that have been reported to enhance the osteogenesis through the gene activation of the osteoblast cells. ${ }^{2)-4)}$

Sautier et al. ${ }^{5)}$ reported that the enhanced proliferation of rat chondrocytes and the improved expressions of the chondrogenic molecular markers such as Sox 9 and Runx 2 were observed when the cells were co-cultured with granules of bioactive glasses such as Bioglass ${ }^{\circledR}$. The release of silicate and calcium ions from the bioactive glasses may have enhanced the cartilage formation.

Cartilage is known to have low natural healing capacity. Due to the deficiency of blood supply and the low migration of cells, once they are damaged from an aging-related wear or diseases such as osteoarthritis and rheumatoid arthritis, regeneration rarely occurs, resulting in the loss of their functions. ${ }^{\text {) }}$ The transplantation of the autologous cartilage is the common treatment for damaged cartilage; ${ }^{7)}$ however this method is invasive and often leads to donor site morbidity. Additionally, supply of autologous cartilage is low and hence need for new materials that posses the ability to regenerate cartilage is present.

The injection of polymer beads suspended in biocompatible solutions has been used for maxillofacial surgeries such as augmentation of nose and chin. ${ }^{8-10)}$ This method is also ideal for achieving minimal invasive cartilage reconstruction. An electrospraying method is an effective method for preparing the beads with a narrow distribution of diameters. ${ }^{11)-13)}$ The diameter of the beads is easily controlled by adjusting the physical properties of slurry and also by varying the slurry-feeding rate. It is important

Corresponding author: T. Kasuga; E-mail: kasuga.toshihiro@ nitech.ac.jp to control the diameter of the beads as it effects the biological reaction of surrounding tissues such as phagocytosis or encapsulation by fibrous tissues. ${ }^{14), 15)}$

In our earlier work, siloxane-containing polymer-inorganic (calcium carbonate-vaterite) hybrids with the releasing ability of silicate ion was prepared. ${ }^{16), 17)}$ The materials were shown to enhance proliferation and differentiation of the murine osteoblast-like cells. ${ }^{18)}$ The siloxane containing inorganic particles $(\mathrm{SiV})$ derived from aminopropyltriethoxysilane (APTES) and vaterite was hybridized with poly (L-lactic acid) (PLLA) through the formation of amide bond between siloxane and PLLA through the amino groups and coordination of calcium ion in the vaterite to the carboxylic group in PLLA (these hybrids were denoted as SiPVHs). ${ }^{19)}$

The present paper describes the preparation of bead-shaped SiPVH with ion-releasing ability for the application of minimal invasive cartilage reconstruction. The SiPVH beads with 10, 20 and $60 \mathrm{wt} \%$ of $\mathrm{SiV}$ particles were prepared via the electrospraying method. To evaluate their degradation behavior, the beads were soaked in a Tris buffer solution. The slurry-feeding rate and the $\mathrm{SiV}$ content in the slurry were varied and their effect on bead diameter and morphology was investigated.

\section{Experimental procedure}

\subsection{Preparation of SiV particles}

$\mathrm{SiV}$ particles were prepared using a carbonation method described in our previous report. ${ }^{19)}$ Briefly, $150 \mathrm{~g}$ of $\mathrm{Ca}(\mathrm{OH})_{2}$ and $60 \mathrm{ml}$ of APTES were added into $2000 \mathrm{ml}$ of methanol, stirred with blowing $\mathrm{CO}_{2}$ gas for $75 \mathrm{~min}$ and the resulting slurry was then dried at $110^{\circ} \mathrm{C}$. The dried powders were spherical secondary particles of $\sim 1 \mu \mathrm{m}$ in diameter (specific surface area; $\sim 70 \mathrm{~m}^{2} / \mathrm{g}$ ), consisting of vaterite with siloxane containing $\sim 2 \mathrm{wt} \%$ of silicon.

\subsection{Preparation of SiPVH beads}

PLLA (LACEA ${ }^{\circledR}$; molecular weight, Mw; $\sim 170 \mathrm{kDa}$ ) and SiV particles were melt-blended at $200^{\circ} \mathrm{C}$ to obtain the SiPVH containing 10, 20 and $60 \mathrm{wt} \%$ of $\mathrm{SiV}$, hereafter, these hybrids are denoted by $\mathrm{SiPVH}_{10}, \mathrm{SiPVH}_{20}$ and $\mathrm{SiPVH}_{60}$, respectively. 
Table 1. Preparation conditions of SiPVH beads

\begin{tabular}{ccccc}
\hline Sample & $\begin{array}{c}\text { SiV:PLLA } \\
\text { (mass ratio) }\end{array}$ & $\begin{array}{c}\text { PLLA ratio } \\
\text { in the slurry } \\
\text { [mass \%] }\end{array}$ & $\begin{array}{c}\text { Feeding } \\
\text { rate } \\
{[\mathrm{ml} / \mathrm{min}]}\end{array}$ & $\begin{array}{c}\text { Applied } \\
\text { voltage } \\
{[\mathrm{kV}]}\end{array}$ \\
\hline $\mathrm{SiPVH}_{10}$ & $10: 90$ & 5 & 0.7 & 17 \\
$\mathrm{SiPVH}_{20}$ & $20: 80$ & 5 & $0.1-0.9$ & 19 \\
$\mathrm{SiPVH}_{60}$ & $60: 40$ & 5 & 0.5 & 19 \\
\hline
\end{tabular}

The beads were prepared via an electrospraying method. ${ }^{12)}$ For the investigation of $\mathrm{SiV}$ particle content on the bead morphology and ion-releasing ability, slurries for the electrospraying was prepared by dissolving $1.1 \mathrm{~g}$ of $\mathrm{SiPVH}_{10}, 1.3 \mathrm{~g}$ of $\mathrm{SiPVH}_{20}$ and $2.5 \mathrm{~g}$ of $\mathrm{SiPVH}_{60}$ containing $0.1,0.3$ and $1.5 \mathrm{~g}$ of $\mathrm{SiV}$ particles, respectively into $19.0 \mathrm{~g}$ of chloroform. The final PLLA to chloroform of $5 \%$ in mass ratio was achieved for the slurries. Table 1 shows the slurries and processing conditions used to prepare the beads. In order to investigate the effect of the feeding rate on the SiPVH beads diameter, the electrospraying of the $\mathrm{SiPVH}_{20}$ was performed by varying the feeding rate from 0.1 to $0.9 \mathrm{ml} / \mathrm{min}$. The voltage applied to the capillary was adjusted to the minimum value at which a slurry-jet was stably formed. A glass dish filled with ethanol was used as the collector, which was stirred to avoid the aggregation of the beads.

The morphologies of the beads and their fracture faces were observed with a scanning electron microscope (SEM) (JEOL, JSM-6301F). The average diameter and standard deviation of the beads were measured from the SEM images using Image-J software (http://rsbweb.nih.gov/ij/) $(n=50)$. The beads were treated as they were spherical during the measurement.

\subsection{Evaluation of silicate and calcium ion-releas- ing behaviors}

$50 \mathrm{mg}$ of the $\mathrm{SiPVH}_{10}$ beads prepared with the slurry-feeding rate of $0.7 \mathrm{ml} / \mathrm{min}$ and the $\mathrm{SiPVH}_{20}$ and $\mathrm{SiPVH}_{60}$ beads prepared with the rate of $0.5 \mathrm{ml} / \mathrm{min}$ were soaked in $10 \mathrm{ml}$ of Tris buffer solution of $\mathrm{pH} 7.4$ and maintained at $37^{\circ} \mathrm{C}$ for $168 \mathrm{~h}$. After the soaking, the beads were filtrated and dried at $50^{\circ} \mathrm{C}$ for $1 \mathrm{~d}$. The weight-average molecular weights $\left(\mathrm{M}_{\mathrm{w}}\right)$ of PLLA in the beads after soaking were estimated with a gel permeation chromatograph (GPC) (Shimadzu, RID-10A), equipped with two columns (Shodex, KF-604). $\mathrm{Si}^{4+}$ and $\mathrm{Ca}^{2+}$ ion concentrations in the solutions were evaluated with an inductively coupled plasma atomic emission spectrometer (ICP-AES) (Shimadzu, ICPS7000). Note that the amount of ionic silicon-species is measured as that of $\mathrm{Si}^{4+}$ ion.

\section{Results and discussion}

Figure 1 shows the SEM images of SiPVH beads. Figures $1(\mathrm{a}-\mathrm{c})$ shows the entire shapes of $\mathrm{SiPVH}$ beads. The average diameters of the $\mathrm{SiPVH}_{10}, \mathrm{SiPVH}_{20}$ and $\mathrm{SiPVH}_{60}$ beads were measured to be $\sim 110, \sim 150$ and $\sim 130 \mu \mathrm{m}$, respectively. Depressed areas can be observed on the surface of the beads, while some of the beads have shrunk and remained spherical. During the electrospraying, on the droplet from the jet a layer of stiff shell forms due to the rapid evaporation of solvent. The inside of the beads, however, would still be wet. The beads then collect into the ethanol and the solvent inside of the beads slowly diffuse out, resulting in the depressions and the deformations. The surface irregularity of the obtained beads might be beneficial for cartilage regeneration, as often the migration of injected materials from the regeneration site is reported to be one of the main problems. Therefore these surface roughness may enable

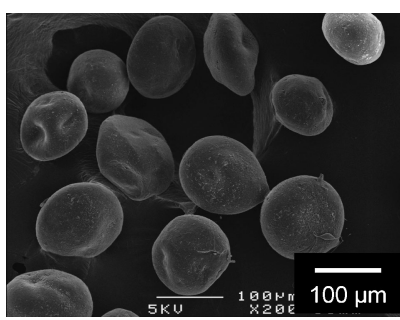

(a)

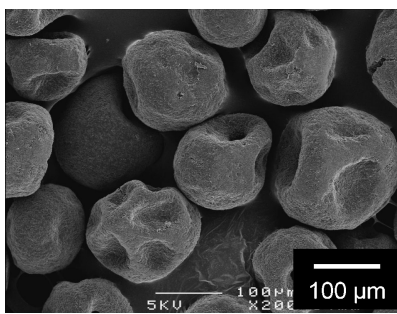

(c)

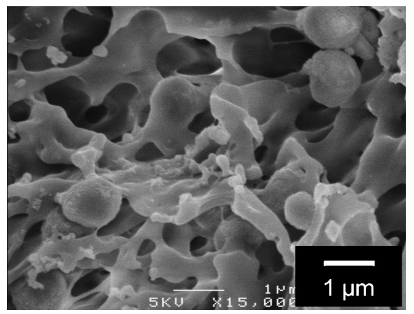

(e)

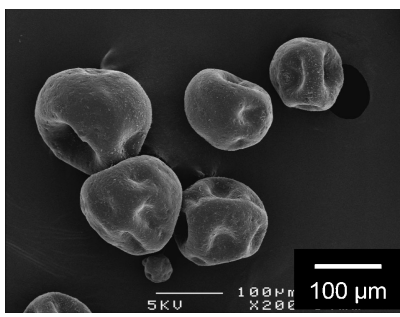

(b)

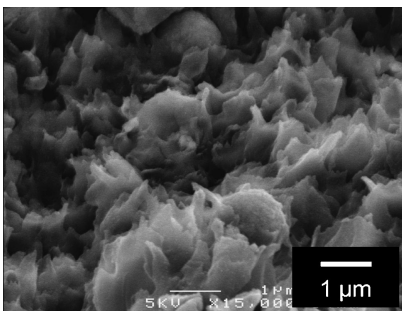

(d)

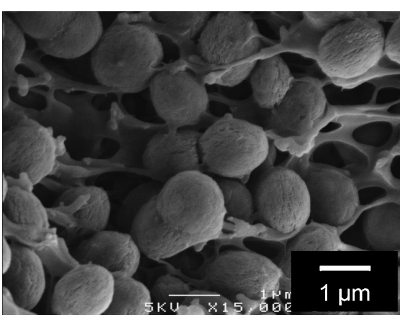

(f)
Fig. 1. SEM images of SiPVH beads containing (a, d) $10 \mathrm{wt} \%$, (b, e) $20 \mathrm{wt} \%$ and (c, f) $30 \mathrm{wt} \% \mathrm{SiV}$ particles in PLLA matrix. (d-f) are fracture faces of $(\mathrm{a}-\mathrm{c})$, respectively.

entanglement and remain in regeneration site. Figures $1(\mathrm{~d}-\mathrm{f})$ shows the SEM images of the fracture face of $\mathrm{SiPVH}_{10}, \mathrm{SiPVH}_{20}$ and $\mathrm{SiPVH}_{60}$. In the $\mathrm{SiPVH}_{10}$ and the $\mathrm{SiPVH}_{20}$ beads, SiV particles are embedded and enclosed by the PLLA matrix. Furthermore, the matrix formed in the $\mathrm{SiPVH}_{10}$ beads appeared to contain smaller amount of pores than that in $\mathrm{SiPVH}_{20}$ beads. On the other hand, in the $\mathrm{SiPVH}_{60}$ beads the particles are in close contact and they are only partially covered with a thin PLLA film. This suggests that the mass ratio between the PLLA and the $\mathrm{SiV}$ particles effects the embedding of the particles in the PLLA matrix.

Figure 2 shows the average diameters of $\mathrm{SiPVH}_{20}$ bead as a function of slurry-feeding rate. The diameter increased from $\sim 65$ to $\sim 180 \mu \mathrm{m}$ by increasing the feeding rate from 0.1 to 0.9 $\mathrm{ml} / \mathrm{min}$. The figure also shows that the size distribution of the beads widens at high feeding rates. During the electrospraying, a highly charged solution forms a conical shape (Taylor cone) at the tip of the capillary. At the apex of the Taylor cone a fine liquid jet forms, which breaks up to fine droplets. ${ }^{13)}$ Increasing the feeding rate increases the volume of materials in the jet. This results in the formation of the large-sized droplets.

Figure 3 shows $\mathrm{Si}^{4+}$ and $\mathrm{Ca}^{2+}$ ions concentrations in the Tris buffer solutions after soaking the beads for given length of time. The SiV content in the beads plays an important role in the amount and rate of ions released, where the higher release is found in the samples containing larger amount of $\mathrm{SiV}$. In the $\mathrm{SiPVH}_{10}$ and $\mathrm{SiPVH}_{20}$ beads, continuous slow releases of the ions were observed after the first $12 \mathrm{~h}$ of soaking. From the $\mathrm{SiPVH}_{10}$ beads, $0.3-0.7 \mathrm{mg} / \mathrm{L}$ of $\mathrm{Si}^{4+}$ and $1.2-2.9 \mathrm{mg} / \mathrm{L}$ of $\mathrm{Ca}^{2+}$ 


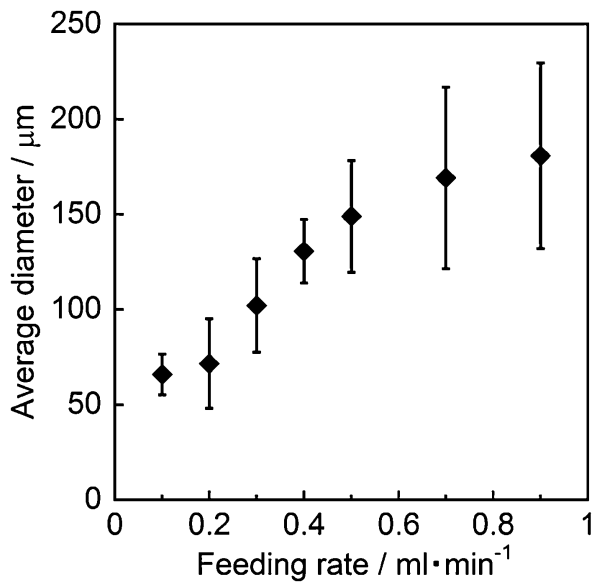

Fig. 2. Average diameters of $\mathrm{SiPVH}_{20}$ beads as a function of slurryfeeding rate during electrospraying.

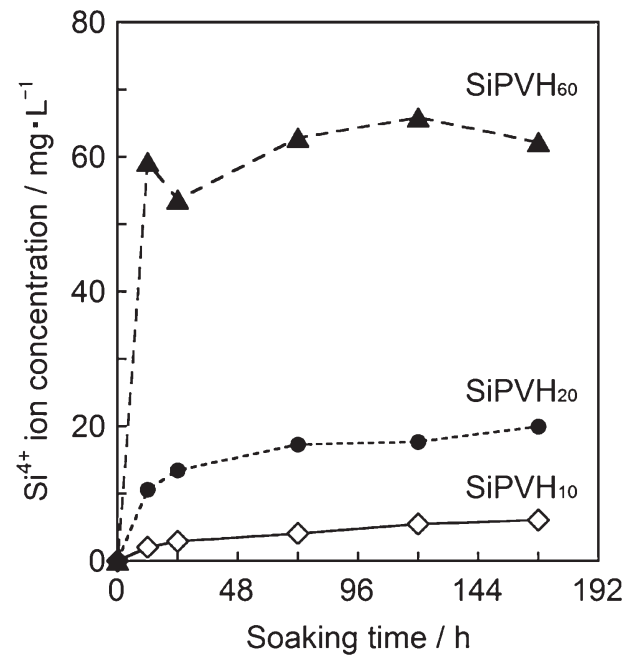

(a)

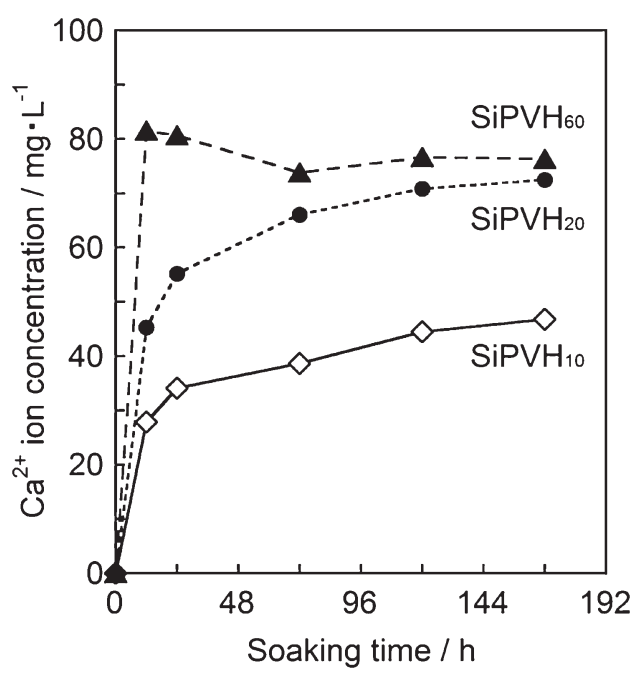

(b)

Fig. 3. Amount of (a) $\mathrm{Si}^{4+}$ and (b) $\mathrm{Ca}^{2+}$ ions released from the beads into a Tris buffer solution after the given period of soaking.

ions were released per day, while $0.4-3.8 \mathrm{mg} / \mathrm{L}$ of $\mathrm{Si}^{4+}$ and $1.7-$ $10.9 \mathrm{mg} / \mathrm{L}$ of $\mathrm{Ca}^{2+}$ ions were released from the $\mathrm{SiPVH}_{20}$ beads in the same period. The $\mathrm{SiPVH}_{60}$ exhibited rapid ion dissolution in

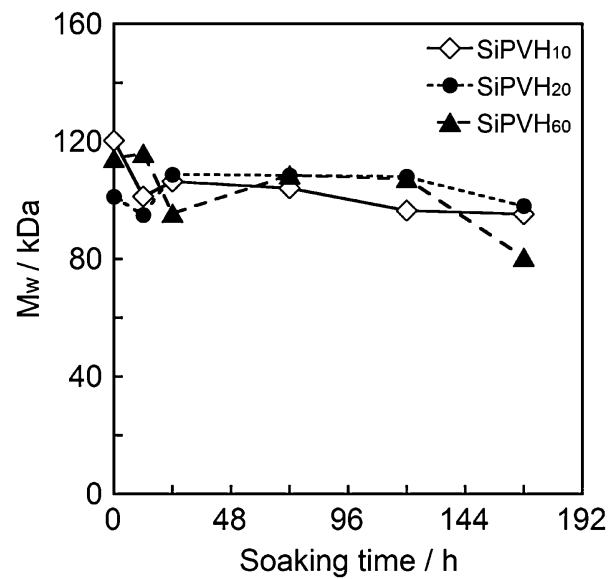

Fig. 4. Weight-average molecular weights $\left(\mathrm{M}_{\mathrm{w}}\right)$ of PLLA in the SiPVH beads after soaking in Tris buffer solution.

the first $12 \mathrm{~h}$ of soaking. The amount of $\mathrm{Si}^{4+}$ and $\mathrm{Ca}^{2+}$ ions dissolved from the beads were measured to be 59 and $81 \mathrm{mg} / \mathrm{L}$, respectively. After the first $12 \mathrm{~h}$, the controlled dissolution of both the ions was found. The ionic silicon-species were suggested to be released as silicate ions from the beads. Figure 4 shows $\mathrm{M}_{\mathrm{w}}$ of PLLA in the SiPVH beads as a function of soaking in a Tris buffer solution. The $\mathrm{M}_{\mathrm{w}}$ values measured with GPC are believed from our preliminary experiments to include their error range within $30 \mathrm{kDa}$. Almost no change in $\mathrm{M}_{\mathrm{w}}$ could be observed, indicating that the PLLA did not degrade in a Tris buffer solution.

In the case of conventional polymer composites having releasing ability of drugs, the releases are facilitated by their degradation. From the SiPVH beads, however, the ions were released from the materials before the onset of the $\mathrm{M}_{\mathrm{w}}$ decrease. Thus, the ions were released independent of polymer degradation. Navarro et al. ${ }^{20)}$ reported the formation of apatite in SBF on a PLA/calcium phosphate glass particle composite where the bioactive calcium phosphate phase was enclosed by the PLA matrix. They proposed that the aqueous solutions penetrate through the polymer and reacts with the glass particles to form apatite. In the $\mathrm{SiPVH}_{10}$ and $\mathrm{SiPVH}_{20}$ beads, dissolution of the $\mathrm{SiV}$ particles probably occurs by the slow diffusion of the Tris buffer solution which penetrates through the PLLA matrix. The silicate and calcium ions released from the particle also penetrate through the matrix into the solution in a control manner, and this gave rise to the slow and continuous release of these ions. Furthermore, the particles in the $\mathrm{SiPVH}_{10}$ beads were much more enclosed than those in the $\mathrm{SiPVH}_{20}$ beads, which will suppress the diffusion of a Tris buffer solution, resulting in the slowest dissolution. In the $\mathrm{SiPVH}_{60}$ beads, the $\mathrm{SiV}$ particles were not entirely covered by PLLA and the beads were also observed to be porous both inside and outside. Therefore they will dissolve immediately into a Tris buffer solution after the soaking. That is, the releasing behaviors of the ions are regulated by the embedding structure of the $\mathrm{SiV}$ particles.

\section{Summary}

The SiPVH beads were successfully prepared by an electrospraying method and the diameter of the beads could be manipulated from $\sim 65$ to $\sim 180 \mu \mathrm{m}$ by changing the feeding rate and the $\mathrm{SiV}$ content in the beads. $\mathrm{SiPVH}_{10}$ and $\mathrm{SiPVH}_{20}$ beads showed the sustained release of silicate and $\mathrm{Ca}^{2+}$ ions, while $\mathrm{SiPVH}_{60}$ showed rapid initial dissolution. This variation in 
ion dissolution behavior originates largely from the differences in the embedding and enclosing of $\mathrm{SiV}$ particles in the PLLA matrix.

Cell culture tests and other investigations are under way to test the beads for the application to an injectable scaffold with controlled ion-releasing ability.

Acknowledgement The authors are indebted to Dr. Yoshio Ota of Yabashi Industries., Co. Ltd. for his helpful discussion. This work was supported in part by a Grant-in-Aid for Scientific Research (B) (\#20390497) from Japan Society for the Promotion of Science (JSPS).

\section{References}

1) L. L. Hench and J. M. Polak, Science, 295, 1014-1017 (2002).

2) I. D. Xynos, A. J. Edgar, L. D. Buttery, L. L. Hench and J. M. Polak, Biochem. Biophys. Res. Commun., 276, 461-465 (2000).

3) J. R. Jones, O. Tsigkou, E. E. Coates, M. M. Stevens, J. M. Polak and L. L. Hench, Biomaterials, 28, 1653-1663 (2007).

4) J. E. Gough, J. R. Jones and L. L. Hench, Biomaterials, 25, 2039-2046 (2004).

5) A. Asselin, S. Hattar, M. Oboeul, D. Greenspan, A. Berdal and J. M. Sautier, Biomaterials, 25, 5621-5630 (2004).

6) S. W. O'driscoll, J. Bone Joint Surg., 80-A, 1795-1813 (1998).

7) M. Brittberg, A. Lindahl, A. Nilsson, C. Ohlsson, O. Isaksson and L. Peterson, N. Engl. J. Med., 14, 889-895 (1994).
8) R. A. Ersek, R. B. Stovall and A. Vazquez-Salisbury, Plast. Reconstr. Surg., 95, 985-993 (1995).

9) R. A. Ersek and A. A. Beisang, III, Plast. Reconstr. Surg., 87, 693-702 (1991).

10) G. Lemperle, V. Morhenn and U. Charrier, Aesthetic Plast. Surg., 27, 354-366 (2003).

11) R. P. A. Hartman, D. J. Brunner, D. M. A. Camelot, J. C. M. Marijnissen and B. Scarlet, J. Aerosol Sci., 30, 823-849 (1999).

12) J. Xie, L. K. Lim, Y. Phua, J. Hua and C. H. Wang, J. Colloid Interface Sci., 302, 103-112 (2006).

13) K. Tang and A. Gomez, J. Colloid Interface Sci., 184, 500-511 (1996).

14) S. Prior, B. Gander, N. Blarer, H. P. Merkle, M. L. Subirá, J. M. Irached and C. Gamazo, Eur. J. Pharm. Sci., 15, 197-207 (2002).

15) M. H. Mankani, S. A. Kuznetsov, B. Fowler, A. Kingman and P. G. Robey, Biotechnol. Bioeng., 72, 96-107 (2000).

16) H. Maeda, T. Kasuga and L. L. Hench, Biomaterials, 27, 1216-1222 (2006).

17) H. Maeda and T. Kasuga, J. Biomed. Mater. Res. A, 85, 742746 (2008).

18) A. Obata and T. Kasuga, J. Biomed. Mater. Res. A, 85, 140144 (2008).

19) A. Obata, S. Tokuda and T. Kasuga, Acta Biomater., 5, 57-62 (2009).

20) M. Navarro, C. Aparicio, M. Charles-Harris, M. P. Ginebra, E. Engel and J. A. Planell, Adv. Polym. Sci., 200, 209-231 (2006). 